\title{
Design, Synthesis, and Functional Evaluation of 1, 5-Disubstituted Tetrazoles as Monoamine Neurotransmitter Reuptake Inhibitors
}

\author{
Suresh Paudel ${ }^{1, \dagger}$, Shuji Wang ${ }^{1, \dagger}$, Eunae Kim ${ }^{2, \dagger}$, Dooti Kundu', Xiao Min ${ }^{1}$, Chan Young Shin ${ }^{3, *}$ and \\ Kyeong-Man $\mathrm{Kim}^{1, *}$ \\ ${ }^{1}$ College of Pharmacy, Chonnam National University, Gwangju 61186, \\ ${ }^{2}$ College of Pharmacy, Chosun University, Gwangju 61452, \\ ${ }^{3}$ Department of Pharmacology and Department of Advanced Translational Medicine, School of Medicine, Konkuk University, Seoul \\ 05029, Republic of Korea
}

\begin{abstract}
Tetrazoles were designed and synthesized as potential inhibitors of triple monoamine neurotransmitters (dopamine, norepinephrine, serotonin) reuptake based on the functional and docking simulation of compound $\mathbf{6}$ which were performed in a previous study. The compound structure consisted of a tetrazole-linker $(\mathrm{n})$-piperidine/piperazine-spacer $(\mathrm{m})$-phenyl ring, with tetrazole attached to two phenyl rings (R1 and R2). Altering the carbon number in the linker (n) from 3 to 4 and in the spacer ( $m$ ) from 0 to 1 increased the potency of serotonin reuptake inhibition. Depending on the nature of piperidine/piperazine, the substituents at R1 and R2 exerted various effects in determining their inhibitory effects on monoamine reuptake. Docking study showed that the selectivity of tetrazole for different transporters was determined based on multiple interactions with various residues on transporters, including hydrophobic residues on transmembrane domains 1, 3, 6, and 8. Co-expression of dopamine transporter, which lowers dopamine concentration in the biophase by uptaking dopamine into the cells, inhibited the dopamine-induced endoctytosis of dopamine $\mathrm{D}_{2}$ receptor. When tested for compound $\mathbf{4 0}$ and $\mathbf{5 6}$, compound $\mathbf{4 0}$ which has more potent inhibitory activity on dopamine reuptake more strongly disinhibited the inhibitory activity of dopamine transporter on the endocytosis of dopamine $D_{2}$ receptor. Overall, we identified candidate inhibitors of triple monoamine neurotransmitter reuptake and provided a theoretical background for identifying such neurotransmitter modifiers for developing novel therapeutic agents of various neuropsychiatric disorders.
\end{abstract}

Key Words: Tetrazoles, Triple reuptake, Transporter, Structure-activity relationship, Docking simulation, Receptor endocytosis

\section{INTRODUCTION}

Tetrazoles are metabolically stable and structurally flexible (Singh et al., 1980; Herr, 2002), which allows their convenient adaption to diverse binding modes (Burger, 1991; Dhayanithi et al., 2011). Tetrazoles are recommended as bioisosteres of carboxylic acid, and thus, have been utilized for synthesizing various chemical compounds, including explosives, oxidizers, and plant growth regulators (John et al., 1989; Klapötke et al., 2009). Moreover, various therapeutic agents, including losartan, candesartan, and dimethyl thiazolyl diphenyl tetrazolium, possess a tetrazole structure (Mosmann, 1983; Dahlof et al., 2002). Tetrazoles with substituents at various positions exhibit diverse pharmacological effects, including antifungal (Ichikawa et al., 2000), antibacterial (Martirosyan et al., 2001), antihypertensive (Le Bourdonnec et al., 2000), antiviral (Hutchinson and Naylor, 1985), anticonvulsive (Wagle et al., 2009), triple monoamine neurotransmitter reuptake inhibitory (Paudel et al., 2017a), growth hormone secretagogue transporter agonistic (Wagner et al., 2004), anti-inflammatory and analgesic (Rajasekaran and Thampi, 2004), anticancer (El-Sayed et al., 2012), anti-diabetic (Gao et al., 2010), antioxidant (Pegklidou

Received Jul 15, 2021 Revised Oct 20, 2021 Accepted Oct 26, 2021 Published Online Nov 18, 2021

\section{*Corresponding Authors}

E-mail: chanyshin@kku.ac.kr (Shin CY), kmkim@jnu.ac.kr (Kim KM) Tel: +82-2-454-5630 (Shin CY), +82-62-530-2936 (Kim KM) Fax: +82-2-2030-7899 (Shin CY), +82-62-530-2949 (Kim KM) ${ }^{\dagger}$ The first three authors contributed equally to this work. 


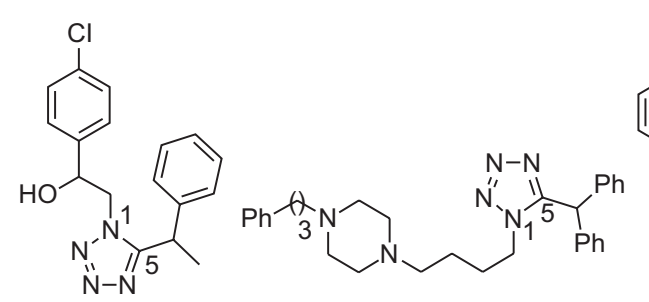

5: Anticonvulsant

6: Triple reuptake inhibitor<smiles>CC(C)(C)C(=O)NC(COCc1ccccc1)c1nnnn1CCOC(=O)NCCCCO</smiles>

7: GHS receptor agonist<smiles>O=C(c1ccc(Cl)cc1)n1nnnc1CCN1c2ccccc2Sc2ccccc21</smiles>

8: Antiinflammatory \&
analgesic<smiles></smiles>

3: Anti-hypertensive

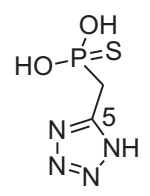

4: Anti-viral

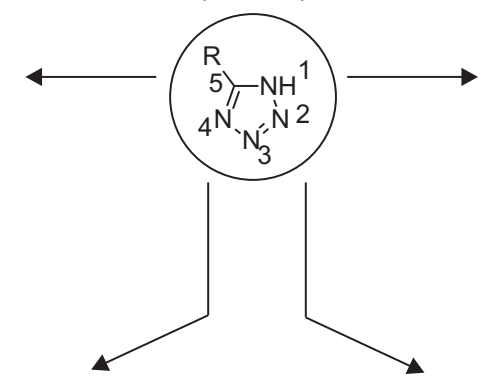<smiles>O=C(Cn1nnc(C2C(c3ccccc3)=Cc3ccccc32)n1)N/N=C/c1ccc(F)cc1</smiles>

9: Anticancer

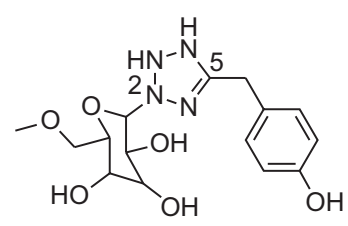

10: Anti-diabetic<smiles>O=C(C1=CC=CC1c1nn[nH]n1)c1ccccc1</smiles>

11: Anti-oxidant<smiles>CC(c1ccc(F)cc1)(c1cccnc1)N1CCN(c2ccc(-n3cnnn3)cc2)C1=O</smiles>

1: Antifungal<smiles>N#[13C]C1=C(CSc2cscn2)SC2C(NC(=O)Cn3cnnn3)C(=O)N12</smiles>

2: Antibacterial $\stackrel{2}{\mathrm{~N}}-\mathrm{N}$ N<smiles>CNC(=O)C1c2ccccc2Oc2ccccc21</smiles>

12: CNS disorders

Fig. 1. Pharmacological application of tetrazole derivatives.

et al., 2010), and metabotropic glutamate transporter type 1 agonistic (Vieira et al., 2005) activities (Fig. 1). Based on these diverse pharmacological activities of tetrazoles, in the present study, we designed, synthesized, and evaluated the biological effects of carboxamides (bioisostere of tetrazoles), ether (functional group change), and tetrazole derivatives.

Monoamines neurotransmitters, dopamine (DA), norepinephrine (NE), and serotonin (5-HT) play important roles in various neuropsychiatric disorders (Hirschfeld, 2000; Belmaker and Agam, 2008). 5-HT and NE play central roles in the development of depression (Holtzheimer and Nemeroff, 2006; Iversen, 2006; Kulkarni and Dhir, 2009), and current therapies mostly target them (Fig. 2) (Subbaiah, 2018). However, they have a slow onset of action and other associated side effects (Prins et al., 2011), which may help explain the low remission rates. The incorporation of DA components into a selective 5-HT reuptake inhibitor or dual reuptake inhibitors has been recommended as one of the strategies to develop safer and more effective therapeutic agents against depression (Paudel et al., 2021). Therefore, triple reuptake inhibitors, which inhibit reuptake of 5-HT, NE, and DA, are gaining increasing attention for the treatment of depression through increase DA neurotransmission, which is not often achieved by conventional treatments (Subbaiah, 2018).

In our previous investigation, we performed functional and docking analysis of compound 6 (Paudel et al., 2017b). Compound 6 showed potent inhibitory effects against three reuptake transporters $\left(\mathrm{IC}_{50}, 158.7 \mathrm{nM}\right.$ for $5-\mathrm{HT}$; $99 \mathrm{nM}$ for NE; 97.5 nM for DA) (Paudel et al., 2017a). Docking simulation revealed that tetrazoles possess a moiety that interacts with amino acids Tyr175 and Thr497 surrounding the ligand-binding pocket (LBP) of human 5-HT transporter (hSERT) (Coleman et al., 2016; Paudel et al., 2017b). Approximately 3 to 4 carbons were required in the linker to provide the flexibility needed to achieve optimal placement of the compound into the L-shaped pocket. A relatively longer linker was necessary to attain the flexible angular conformation for accommodating into the LBP. Accordingly, new derivatives were designed by altering Ar1 and Ar2 while maintaining the essential tetrazole moiety (Fig. 3).

Thus, in this study, we designed, synthesized, and analyzed their structure-activity relationship. In addition, we conducted docking simulation for 1,5-disubstituted tetrazoles for their interaction with human dopamine transporter (hDAT) and hSERT. Finally, we determined the effects of hDAT inhibitors on the hDAT-mediated regulation of dopamine $D_{2}$ receptor 
A<smiles>NCCc1c[nH]c2ccc(O)cc12</smiles>

Serotonin<smiles>NC[C@@H](O)c1ccc(O)c(O)c1</smiles>

Norepinephrine<smiles>NCCc1ccc(O)c(O)c1</smiles>

Dopamine
B<smiles>CNCCC(Oc1ccc(C(F)(F)F)cc1)c1ccccc1</smiles>

Fluxetine<smiles>Fc1ccc(C2CCNCC2COc2ccc3c(c2)OCO3)cc1</smiles>

Paroxetine<smiles>CCCCC(O)(CC)C(CC)c1ccc(OC)cc1</smiles>

Venlafaxine

Lu-AA42202

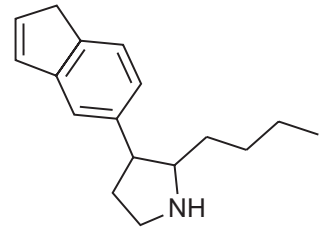

RG-7166
Milnacipran<smiles>CN[C@H]1C[C@H](c2c[nH]c3c(F)cccc23)c2ccccc21</smiles><smiles>CCNC(=O)C1(c2ccccc2)CC1CN</smiles>

NS-2359<smiles>Clc1ccc([C@]23CNCC2C3)cc1Cl</smiles>

DOV-21,947<smiles>N[C@H]1CC[C@@H](c2ccc(Cl)c(Cl)c2)c2ccccc21</smiles>

SEP-225289

Fig. 2. Chemical structures of monoamines and related reuptake inhibitors. (A) Chemical structure of three monoamine neurotransmitters. (B) Structures of marketed single and dual reuptake inhibitors. (C) Several classes of triple reuptake inhibitors in preclinical or early clinical stages of development.

functions.

\section{MATERIALS AND METHODS}

\section{Reagents}

GBR12909 dihydrochloride was purchased from Tocris Bioscience (Bristol, UK). Venlafaxine hydrochloride and do- pamine were obtained from Sigma-Aldrich Chemical Co (St. Louis, MO, USA). $\left[{ }^{3} \mathrm{H}\right]-\mathrm{DA},\left[{ }^{3} \mathrm{H}\right]-5-\mathrm{HT}$, and $\left[{ }^{3} \mathrm{H}\right]$-sulpiride were purchased from PerkinElmer Life Sciences (Waltham, MA, USA). Human embryonic kidney (HEK)-293 cells were obtained from the American Type Culture Collection (Manassas, VA, USA) and maintained in minimal essential medium containing $10 \%$ fetal bovine serum, $100 \mathrm{U} / \mathrm{mL}$ penicillin, and 100 $\mu \mathrm{g} / \mathrm{mL}$ streptomycin. 


\section{Chemistry}

Detailed synthetic procedures for generating 1, 5-disubstituted tetrazoles are shown in Scheme 1. Substituted benzhydrol 13c was refluxed overnight with excess thionyl chloride to obtain crude product 14c. The chloro-substituted diphenylmethanes (14b-14d) and trimethylsilyl cyanide were reacted in the presence of titanium chloride $\left(\mathrm{TiCl}_{4}\right)$ to generate distinct substituted diphenyl acetonitriles (15a-15d). Substituted diphenyl acetonitriles (15a-15d) were refluxed with excess sodium azide and triethylamine hydrochloride to obtain substituted 5-benzhydryl-1H-tetrazoles (16a-16d). The obtained tetrazoles, 16a-16d, were further reacted with 1-bromo3-chloropropane or 1-bromo-4-chlorobutane to generate vari-

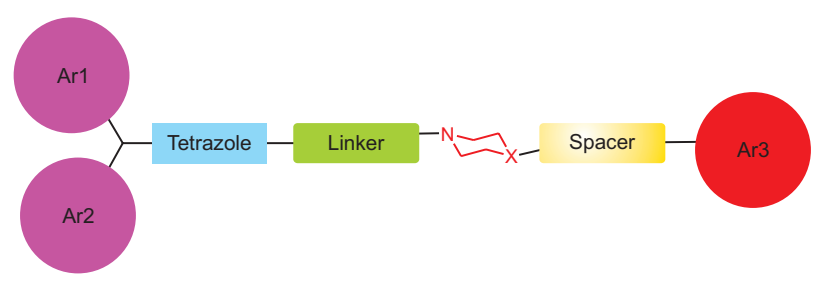

Fig. 3. Structural outline of newly designed reuptake inhibitor, 1, 5-disubstituted tetrazoles. ous haloalkyl-5-benzhydryl-1H-tetrazole $(\mathbf{1 7 a - 1 7 d ~ [ n = 3 ] ~ a n d ~}$ 18a-18d [n=4]).

Conversely, tert-butyl piperazine-1-carboxylate (19) was refluxed with various phenyl alkyl/alkene halides $(20 \mathrm{~g}-20 \mathrm{i})$ to obtain alkyl/alkene aryl tert-butyl piperazine-1-carboxylates (21g-21i), which were later hydrolyzed to obtain alkyl/alkene aryl piperazines $(\mathbf{2 4 g - 2 4 i )}$. Likewise, piperazine 22 was reacted with benzyl bromide (20f) to obtain benzyl piperazine $\mathbf{2 4 f}$.

The substitution reaction of $17 a-17 d(n=3)$ and $18 a-18 d$ $(n=4)$ with commercially available piperidines $(23 e-23 h$ and 23j) and newly synthesized piperazines (24f-24i) resulted in 1 , 5-disubstituted tetrazoles, including 25-36 $(n=3, X=C H)$, 27-56 $(n=4, X=C H)$, and 57-72 $(n=4, X=N)$. More detailed information regarding the synthetic procedure and physicochemical properties of each compound are described in supplemental data.

\section{Docking simulation}

Compound $\mathbf{4 0}$ and $\mathbf{5 4}$ have a high affinity for hDAT and hSERT, respectively, but there was no compound suitable for hNET, so docking simulation was performed only for hDAT and hSERT. The structure of hSERT-paroxetine was available from Protein Data Bank (PDB ID: 5I6X) (Coleman et al., 2016). Ligands such as maltose, cholesterol, $\mathrm{N}$-acetylglucosamine, the chloride ion, and paroxetine (drug) were deleted. hDAT
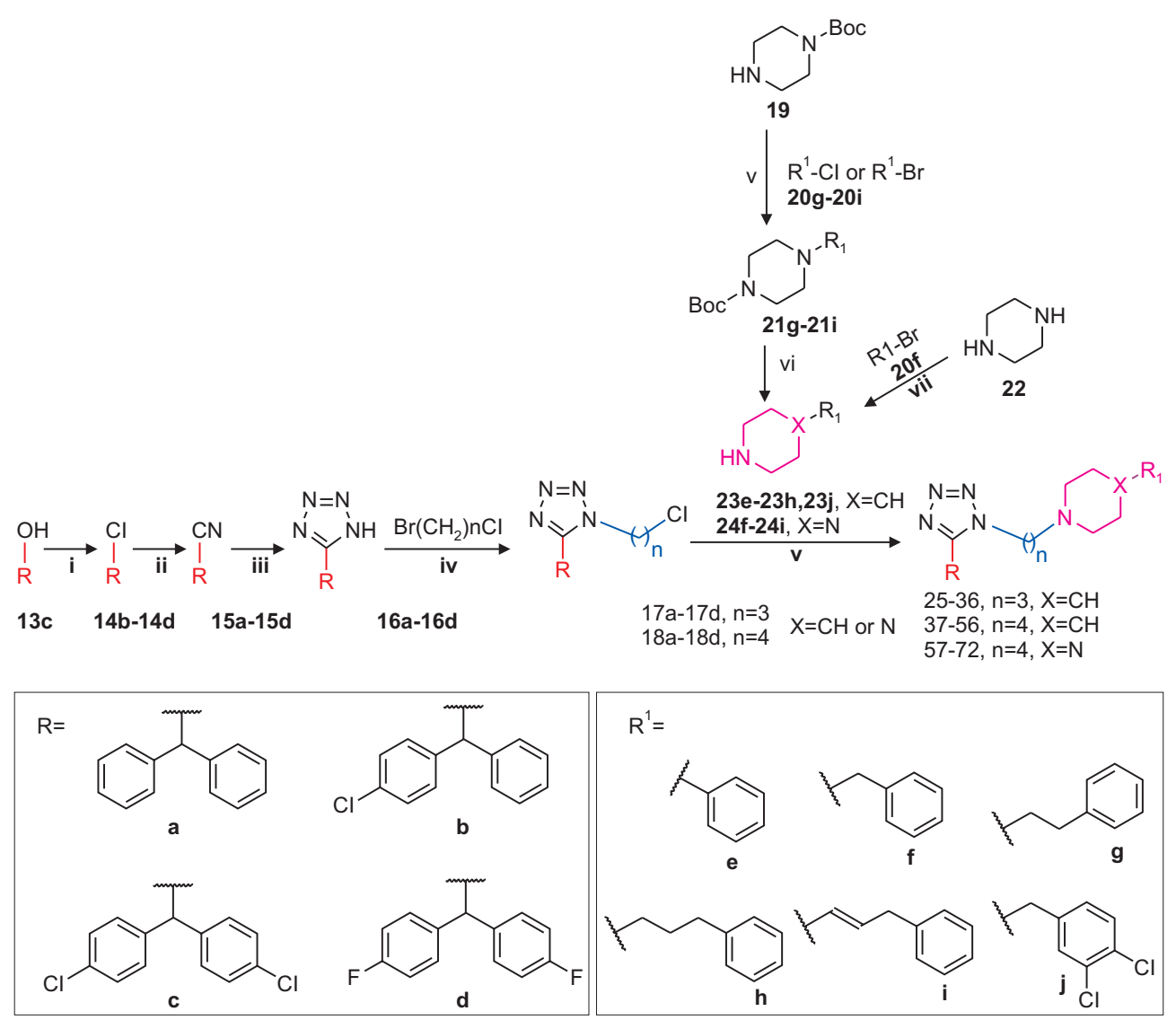

Scheme 1. Reagents and conditions used for the synthesis of 1,5-disubstituted tetrazoles. (i) $\mathrm{SOCl}_{2}$, DMF, reflux. (ii) Trimethylsilyl cyanide. $\left.\left(\mathrm{CH}_{3}\right)_{3} \mathrm{SiCN}\right)$, titanium tetrachloride $\left(\mathrm{TiCl}_{4}\right)$ in $\mathrm{CH}_{2} \mathrm{Cl}_{2}, 0-20^{\circ} \mathrm{C}$. (iii) Sodium azide $\left(\mathrm{NaN}_{3}\right)$, triethylamine hydrochloride $(\mathrm{TEA} \cdot \mathrm{HCl})$, toluene, $100^{\circ} \mathrm{C}$. (iv) $\mathrm{K}_{2} \mathrm{CO}_{3}$, acetone, $20^{\circ} \mathrm{C}$. (v) Acetonitrile $\left(\mathrm{CH}_{3} \mathrm{CN}\right), \mathrm{K}_{2} \mathrm{CO}_{3}, \mathrm{Nal}$, reflux. (vi) Trifluoroacetic acid (TFA), $\mathrm{CH}_{2} \mathrm{Cl}_{2}, 0-20^{\circ} \mathrm{C}$. (vii) $\mathrm{CH}_{2} \mathrm{Cl}_{2}$, $0^{\circ} \mathrm{C}$. 
was constructed by homology modeling, SwissModel (Waterhouse et al., 2018). The template of homology modeling was X-ray structure of Drosophila dopamine transporter (PDB ID: 4XPT) (Wang et al., 2015). The sequence identity of hDAT (Uniprot entry: Q01959) is about $54.8 \%$ compared with the template. The root mean square deviate $(r m s d)$ of the modeling hDAT and $Q$-score of the homology model are about $1.1 \AA$ and 0.798 , respectively. These values mean the model hDAT is very similar to the template and the confidence of the modeling is reasonable.

Hydrogens were added for two target transporters and they were minimized by using Chimera software. The threedimensional (3D) structures of ligands $\mathbf{4 0}$ and $\mathbf{5 4}$ were built by ChemAxon (2014). The docking study was computed by Vina (Trott and Olson, 2010). To set up a search algorithm, the binding site was assigned. Because the substrate-binding pocket is surrounded primarily by helices $1,3,6$, and 8 in close to the ions-binding pocket, the central region of transmembrane helix (TM) 3 with hydrophobic amino acids was suitable for making a curved conformer of ligand. Val152, which is equivalent to the Val120 residue in the Drosophila dopamine transporter, and the lle172 in hSERT, played important roles. In addition, TM1 and TM6 supported several residues that interacted with inhibitors and coordinate $\mathrm{Na}^{+}$and $\mathrm{Cl}^{-}$ions. The search region for the docking simulation was defined by the central ligand pocket including the key residues. According to the score values of the docking simulation, top of binding pose was selected.

The selected complex structure was run by molecular dynamic (MD) simulation to confirm a thermal stability of complex in physiological environment and to overcome the defect of the rigid docking simulation. The cubic simulation box of the complex was solvated by TIP3P water model (Jorgensen et al., 1983) and total charge of the system was neutralized by adding ions. The structural force field of protein and ligand were applied by AMBER14SB (Maier et al., 2015) and GAFF (Sprenger et al., 2015), respectively. After energy minimization, MD was performed at $310 \mathrm{~K}$ and $1 \mathrm{~atm}$. The time step was about 2 fs using LINCS algorithm, (Hess et al., 1997) which fix the bond including a hydrogen atom. The periodic boundary condition was used with Particle-Mesh Ewald (PME) and the cutoff of long-range electrostatics was $10 \AA$. To equilibrate the system, total run time was selected as about 100 ns. All MD simulations were conducted by Gromacs software (Abraham et al., 2015). The last 50 ns data was converged and analyzed by LigPlot (Laskowski and Swindells, 2011) and Chimera software (Pettersen et al., 2004).

\section{Neurotransmitter uptake assay}

The assay was performed in accordance with the method described in the literature with a slight modification (Paudel et al., 2015). HEK-293 cells were cultured in a medium supplemented with fetal bovine serum and transfected with hSERT, hNET, or hDAT. Radiolabeled $\left[{ }^{3} \mathrm{H}\right]-5-\mathrm{HT}$ or $\left[{ }^{3} \mathrm{H}\right]-\mathrm{DA}$ were used at a concentration of $20 \mathrm{nM}$. Radioactivity was measured using Wallac 1450 MicroBeta $^{\circledR}$ TriLux liquid scintillation counter (PerkinElmer). Venlafaxine hyrochloride and GBR12909 dihydrochloride were used as reference inhibitors of neurotransmitters reuptake.

To determine the $\mathrm{IC}_{50}$ of the synthesized compounds, the concentration of the compounds was gradually increased and the percentage of inhibition was assessed for each concentra- tion. GraphPad Prism 5 (GraphPad Software, Inc., San Diego, CA, USA) was used to construct the dose-response curve and determine the $\mathrm{IC}_{50}$.

\section{Dopamine $D_{2}$ receptor endocytosis assay}

Endocytosis of dopamine $D_{2}$ receptor $\left(D_{2} R\right)$ was measured based on the hydrophilic properties of $\left[{ }^{3} \mathrm{H}\right]$-sulpiride (Kim et al., 2001). HEK-293 cells transfected with $D_{2} R-p C M V 5$ and GRK2-pRK5 were seeded at a density of $1.5 \times 10^{5}$ cells/well in 24-well plates. After $24 \mathrm{~h}$, the cells were stimulated with 100 $\mathrm{nM}$ DA for $60 \mathrm{~min}$. Cells were washed three times with warm serum-free media. The cells were then incubated with $250 \mu \mathrm{L}$ of $\left[{ }^{3} \mathrm{H}\right]$-sulpiride (final concentration $2.2 \mathrm{nM}$ ) at $4^{\circ} \mathrm{C}$ for $150 \mathrm{~min}$ in the absence and presence of a competitive inhibitor (10 $\mu \mathrm{M}$ haloperidol). The cells were washed thrice with ice-cold serum-free media and then $1 \%$ sodium dodecyl sulfate was added. The samples were mixed with $2 \mathrm{~mL}$ Lefko-Fluor scintillation fluid and counted on a liquid scintillation analyzer (1450 MicroBeta TriLux, PerkinElmer).

\section{Statistical analysis}

Values are expressed as the mean \pm standard deviation. Statistical significance of the data was analyzed using oneway analysis of variance with Tukey's post hoc test using GraphPad Prism 5. A p-value $<0.05$ was considered significant.

\section{RESULTS}

\section{Structure-activity relationship of piperidine-tetrazoles for monoamine reuptake inhibition}

In an initial study, piperidine-tetrazoles (26-36 and 38-48) were synthesized, and their effects on monoamine reuptake were determined (Table 1).

The compounds designed in this study contain an aliphatic linker with 3 to 4 carbons, along with a variable aromatic region (Ar1), a piperazine/piperidine-aromatic region (Ar2), and an essential functional tetrazole moiety (Fig. 3). To establish the structure-activity relationship (SAR) of piperidine-tetrazoles in terms of monoamine reuptake inhibition, we analyzed the effects of the linker length between tetrazole and piperidine/piperazine ( $n$ ); substitutions at two phenyl rings (R1, R2); and the length of the spacer between piperidine/piperazine and phenyl ring $(\mathrm{m})$.

First, increasing the ' $n$ ' from 3 to 4 strongly increased the inhibitory effect of piperidine-tetrazoles on 5-HT reuptake, without demonstrating any consistent effects on NE and DA reuptake. Thus, changing the linker length could be explored to convert dual reuptake inhibitors (DAT/NET) into triple reuptake inhibitors. Second, compounds with ' $n=3$ ' and chloro groups at R1 and R2 on phenyl groups consistently demonstrated weaker inhibitory effects on NE reuptake. Additionally, the effect of substitutions at R1 and R2 was intermixed with the influence of the linker length, and no clear conclusion could be drawn regarding monoamine reuptake. Finally, compounds with spacer lengths of ' $m=3$ ' revealed weaker inhibitory effect on DAT.

As ' $n$ ' revealed the most prominent effects on 5-HT reuptake, a higher number of piperidine and piperazine derivatives with four-carbon linkers were synthesized. As shown in Table 1 (37-40) and Table 2 (49-56), altering ' $m$ ' from 0 to 1 increased the piperidine-mediated inhibition on $5-\mathrm{HT}$ reup- 
Table 1. Effects of 1, 5-disubstituted tetrazoles on monoamine reuptake inhibition

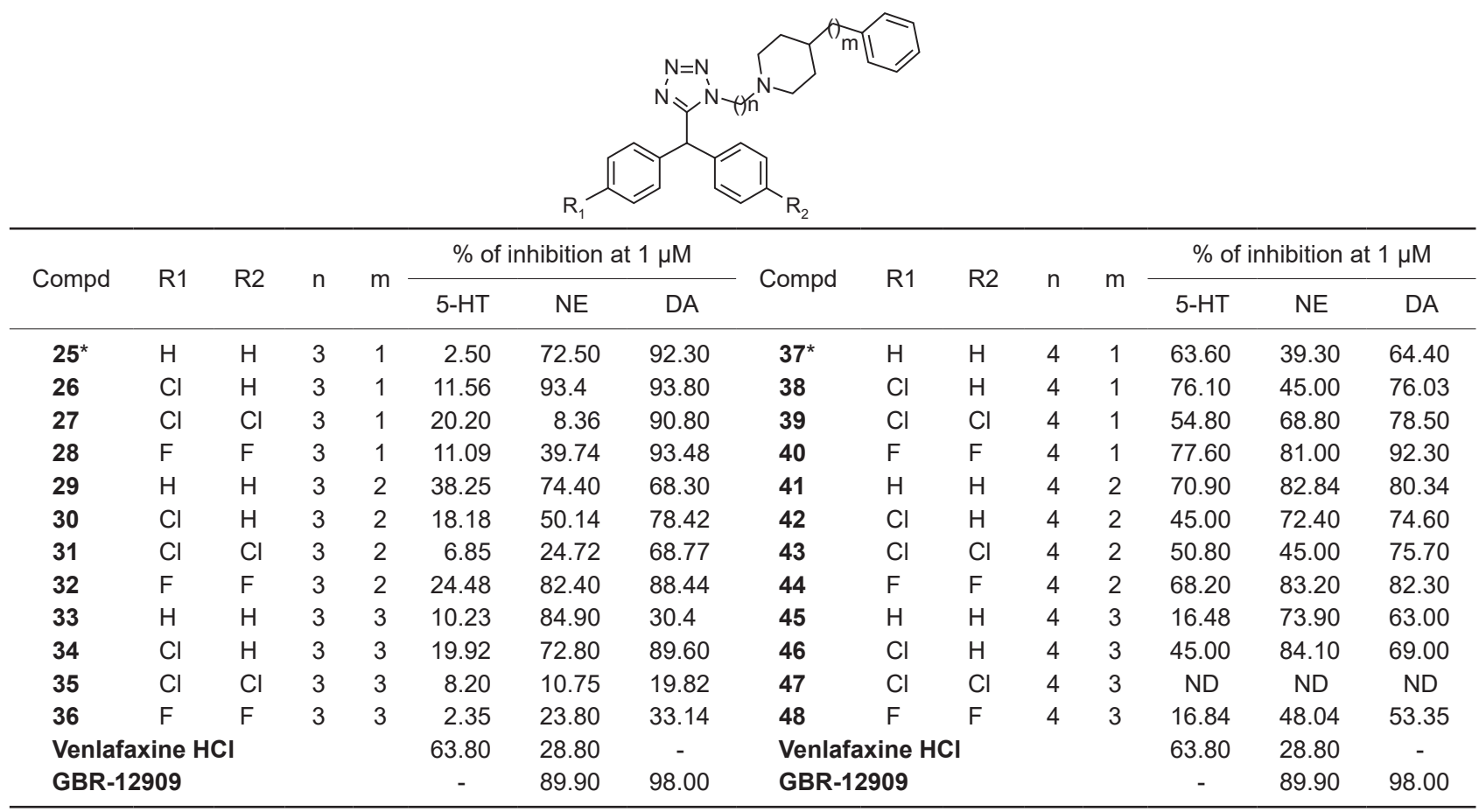

Venlafaxine hydrochloride $(1 \mu \mathrm{M})$ was used as a positive control for $5-\mathrm{HT}$ and NE uptake assay. GBR-12909 dihydrochloride was used as a positive drug for NE and DA reuptake at $1 \mu \mathrm{M}$. $n$ represents the carbon number in the linker between the tetrazole and piperidine group ( $\mathrm{n}=3$, 4 ) and $m$ represents spacer between the piperidine and phenyl group $(m=1-3)$. ND represents 'not determined' due to solubility problem and * denotes Wagner et al (2004).

take. Furthermore, 5-HT reuptake inhibition was increased with compounds having monochloro/difluro substitution at $\mathrm{R} 3$ and $\mathrm{R} 4$ with $\mathrm{m}=1$ (37-40 vs. 53-56). Thus, the 1,5-disubstituted tetrazole-piperazines with ' $n=4$ ', ' $m=1$ ' and $R 3=\mathrm{Cl}$ or $\mathrm{R} 3=\mathrm{R} 4=\mathrm{Cl}$ are expected to exhibit excellent 5-HT reuptake inhibitory effects. Collectively, the results from Table 1 and Table 2 suggest that piperidine-tetrazoles with ' $n=4$ ' and ' $m>0$ ' demonstrate superior 5-HT reuptake inhibitory effect.

To determine the role of substituents at R1, R2, and $m$, additional piperazine derivatives with carbon linker ' $n=4$ ' were synthesized, and their effects on the monoamine reuptake were determined (Table 3). First, no consistent trend was observed when the ' $m$ ' value varied between 1 and 3 or when a double bond was added with ' $m=3$ '. Second, compounds with chloride or fluoride groups at R1 and/or R2 exerted increased inhibitory effect on DA reuptake. Third, compounds possessing fluoride at R1 and R2 demonstrated weaker inhibitory effect on 5 - $\mathrm{HT}$ reuptake with $\mathrm{m}=3$. Fourth, compounds with chloride at R1 and R2 revealed weaker inhibitory effect on NE reuptake, except when $m=1$. Some of these results, for instance, the effects of chloride at R1 and R2 on 5-HT and NE reuptake, in part, agree with the results observed with piperidine compounds (Table 1). However, the effects of chloride and/or fluoride at R1 and R2 on DA reuptake differed from those of piperidines, suggesting that the presence of piperidine or piperazine connected with a tetrazole structure has a distinct impact on monoamine reuptake.

Tetrazoles displaying relatively potent reuptake inhibitory effects were further analyzed to determine their $I_{50}$ (halfmaximal inhibitory concentration) (Table 4).
Table 2. Monoamine reuptake inhibition by additional 1, 5-disubstituted tetrazole-piperidines with 4 carbon spacers

\begin{tabular}{|c|c|c|c|c|c|c|c|}
\hline \multirow{2}{*}{ Compd } & \multirow{2}{*}{$\mathrm{R} 1$} & \multirow{2}{*}{$\mathrm{R} 2$} & \multirow{2}{*}{$\mathrm{m}$} & \multirow{2}{*}{$\mathrm{R} 3=\mathrm{R} 4$} & \multicolumn{3}{|c|}{$\%$ of inhibition at $1 \mu \mathrm{M}$} \\
\hline & & & & & $5-\mathrm{HT}$ & NE & DA \\
\hline 49 & $\mathrm{H}$ & $\mathrm{H}$ & 0 & $\mathrm{H}$ & 7.04 & 66.26 & 93.92 \\
\hline 50 & $\mathrm{Cl}$ & $\mathrm{H}$ & 0 & $\mathrm{H}$ & 33.29 & 46.35 & 92.71 \\
\hline 51 & $\mathrm{Cl}$ & $\mathrm{Cl}$ & 0 & $\mathrm{H}$ & 41.16 & 33.95 & 90.06 \\
\hline 52 & $\mathrm{~F}$ & $\mathrm{~F}$ & 0 & $\mathrm{H}$ & 65.40 & 64.40 & 94.60 \\
\hline 53 & $\mathrm{H}$ & $\mathrm{H}$ & 1 & $\mathrm{Cl}$ & 94.60 & 63.90 & 67.70 \\
\hline 54 & $\mathrm{Cl}$ & $\mathrm{H}$ & 1 & $\mathrm{Cl}$ & 88.90 & 58.90 & 67.80 \\
\hline 55 & $\mathrm{Cl}$ & $\mathrm{Cl}$ & 1 & $\mathrm{Cl}$ & 43.77 & 41.09 & 62.56 \\
\hline 56 & $\mathrm{~F}$ & $\mathrm{~F}$ & 1 & $\mathrm{Cl}$ & 84.80 & 75.90 & 68.90 \\
\hline \multicolumn{4}{|c|}{ Venlafaxine $\mathrm{HCl}$} & & 63.80 & 28.80 & - \\
\hline \multicolumn{4}{|c|}{ GBR-12909 } & & - & 89.90 & 98.00 \\
\hline
\end{tabular}

Venlafaxine hydrochloride $(1 \mu \mathrm{M})$ was used as a positive control for 5-HT and NE uptake assay. GBR-12909 dihydrochloride was used as a positive drug for NE and DA reuptake at $1 \mu \mathrm{M}$. 'm' represents spacer between the piperidine and phenyl group $(m=0-1)$. 
Table 3. Monoamine reuptake inhibition by additional 1, 5-disubstituted tetrazole-piperazine with 4 carbon spacers

\begin{tabular}{|c|c|c|c|c|c|c|c|c|c|c|c|c|c|}
\hline \multirow{2}{*}{ Compd } & \multirow{2}{*}{ R1 } & \multirow{2}{*}{$\mathrm{R} 2$} & \multirow{2}{*}{$\mathrm{m}$} & \multicolumn{3}{|c|}{$\%$ of inhibition at $1 \mu \mathrm{M}$} & \multirow{2}{*}{ Compd } & \multirow{2}{*}{$\mathrm{R} 1$} & \multirow{2}{*}{$\mathrm{R} 2$} & \multirow{2}{*}{$\mathrm{m}$} & \multicolumn{3}{|c|}{$\%$ of inhibition at $1 \mu \mathrm{M}$} \\
\hline & & & & $5-\mathrm{HT}$ & $\mathrm{NE}$ & $\mathrm{DA}$ & & & & & $5-\mathrm{HT}$ & NE & $\mathrm{DA}$ \\
\hline $57^{*}$ & $\mathrm{H}$ & $\mathrm{H}$ & 1 & 7.60 & 60.90 & 76.30 & $65^{*}$ & $\mathrm{H}$ & $\mathrm{H}$ & 3 & 68.10 & 90.00 & 80.50 \\
\hline 58 & $\mathrm{Cl}$ & $\mathrm{H}$ & 1 & 14.60 & 86.50 & 94.70 & 66 & $\mathrm{Cl}$ & $\mathrm{H}$ & 3 & 46.90 & 63.60 & 81.60 \\
\hline 59 & $\mathrm{Cl}$ & $\mathrm{Cl}$ & 1 & 1.12 & 79.03 & 91.68 & 67 & $\mathrm{Cl}$ & $\mathrm{Cl}$ & 3 & 38.53 & 21.29 & 72.67 \\
\hline 60 & $\mathrm{~F}$ & $\mathrm{~F}$ & 1 & 51.40 & 95.00 & 95.70 & 68 & $\mathrm{~F}$ & $\mathrm{~F}$ & 3 & 8.72 & 86.40 & 56.20 \\
\hline $61^{*}$ & $\mathrm{H}$ & $\mathrm{H}$ & 2 & 12.10 & 76.40 & 56.90 & $69^{*}$ & $\mathrm{H}$ & $\mathrm{H}$ & $3^{\star *}$ & 26.30 & 79.70 & 29.00 \\
\hline 62 & $\mathrm{Cl}$ & $\mathrm{H}$ & 2 & 5.04 & 47.65 & 62.06 & 70 & $\mathrm{Cl}$ & $\mathrm{H}$ & $3^{* *}$ & 53.50 & 50.40 & 82.20 \\
\hline 63 & $\mathrm{Cl}$ & $\mathrm{Cl}$ & 2 & 21.33 & 34.58 & 56.81 & 71 & $\mathrm{Cl}$ & $\mathrm{Cl}$ & $3^{* *}$ & 4.04 & 63.01 & 87.35 \\
\hline 64 & $\mathrm{~F}$ & $\mathrm{~F}$ & 2 & 25.24 & 56.91 & 80.35 & 72 & $\mathrm{~F}$ & $\mathrm{~F}$ & $3^{* *}$ & 59.80 & 52.80 & 83.80 \\
\hline \multicolumn{4}{|c|}{ Venlafaxine $\mathrm{HCl}$} & 63.8 & 28.80 & - & \multicolumn{3}{|c|}{ Venlafaxine $\mathrm{HCl}$} & & 63.80 & 28.80 & - \\
\hline \multicolumn{4}{|c|}{ GBR-12909 } & - & 89.90 & 98.00 & \multicolumn{3}{|c|}{ GBR-12909 } & & - & 89.90 & 98.00 \\
\hline
\end{tabular}

Venlafaxine hydrochloride $(1 \mu \mathrm{M})$ was used as a positive control for $5-\mathrm{HT}$ and NE uptake assay. GBR-12909 dihydrochloride was used as a positive drug for NE and DA reuptake at $1 \mu \mathrm{M}$. * denotes Wagner et al (2004). ' $m$ ' represents spacer between the piperazine $(\mathrm{m}=1-3)$ and phenyl group. ${ }^{* *}$ represents ' $\mathrm{m}=\left(\mathrm{CH}_{2} \mathrm{CH}=\mathrm{CH}\right)$ '.

Based on Table 1, we concluded that piperidine-tetrazoles with ' $n=4$ ' exerts stronger inhibitory effect on 5 -HT reuptake than those with ' $n=3$ '; this was confirmed by four cases -26 vs. 38, 29 vs. 41, 32 vs. 44, and 34 vs. 46. Additionally, compounds in series 37-48 displayed lower $\mathrm{IC}_{50}$ S than their corresponding counterparts of series 25-36. Moreover, according to Table 1, piperidine-tetrazoles with ' $m=3$ ' have lower inhibitory effect on DA reuptake than those with ' $m=1$ or 2'; this was confirmed by two examples -34 vs. 26 and 46 vs. 38. The majority of compounds with ' $m=3$ ' showed higher $\mathrm{IC}_{50} \mathrm{~s}$ than those with ' $m=1$ or 2'.

Tetrazoles with potent 5-HT, NE and DA reuptake inhibitory activities ( $\mathrm{RI} \geq 45 \%$ ) were further analyzed to determine $I_{50}$ values The $\mathrm{IC}_{50}$ values of 5-HT, NE and DA reuptake inhibitory activity of the selected compounds are presented in Table 4.

Based on Table 1 and Table 2, it can be concluded that piperidine-tetrazoles with ' $n=4$ ' and ' $m=1$ ' have more potent inhibitory effect on the 5-HT reuptake than compounds with ' $n=4$ ' and ' $m=0$ '; this was confirmed when $\mathbf{5 2}$ was compared with $\mathbf{4 0}$. The $\mathrm{IC}_{50}$ of $\mathbf{5 2}$, which has ' $\mathrm{n}=4$ ' and ' $\mathrm{m}=0$ ', was greater than that of $\mathbf{4 0}$ with ' $n=4$ ' and ' $m=1$ '.

The extent of reuptake inhibition based on primary screening (Table 1-3) corroborated with the $\mathrm{IC}_{50} \mathrm{~S}$ (Table 4). Because DA and NE are structurally similar to each other, most reuptake inhibitors show similar inhibitory effects on them (Paudel et al., 2021). Interestingly, the primary screening results shown in Tables 1 and 2 show that the inhibitory effect on SERT can be increased by changing the linker length ( $n$ and $\mathrm{m}$ ). The dose-response curves of compounds $\mathbf{4 0}$ and $\mathbf{5 4}$ are shown in Supplementary Fig. 1.

\section{Docking simulation}

According to Table 4, compound 40 and compound 54 showed high affinity and selectivity for hDAT and hSERT, respectively. To predict the binding pose of the complex and understand interactions between the transporter and ligand at the atomic level, molecular docking and molecular dynamics simulation were conducted for compounds $\mathbf{4 0}$ and $\mathbf{5 4}$ as binding partners of hDAT and hSERT, respectively. As shown in Fig. 4, compounds $\mathbf{4 0}$ and $\mathbf{5 4}$ bound to the central pocket of hDAT and hSERT, respectively. The compound $\mathbf{4 0}$ was surrounded by hDAT through hydrophobic residues of TM1, TM3, and TM6 (Fig. 4A). The important moiety of the tetrazole ring was sandwiched between Val152, Phe155, and Tyr156 of TM3 and Phe320 of TM6. Thus, it can be postulated that the orientation of the 1-5 disubstituted tetrazole ring is determined by the four hydrophobic residues of TM3 and TM6. The fourcarbon linker of $\mathbf{4 0}$ in the tetrazole ring was curved and Cshaped, covered by the hydrophobic core of TM3 that contains Val152, Phe155, and Tyr156. The branched di-para-fluorobenzyl rings of tetrazole were surrounded with Phe76 of TM1, Tyr156 of TM3 and Phe326 of TM6. In particular, one monofluoro-benzyl ring was attached to Val152 of TM3 in parallel, forming an edge-to-face aromatic interaction with Tyr156 of TM3. The other monofluoro-benzyl ring was fenced in Phe76/ Asp79 of TM1 and Phe326 of TM6. As reported previously that Phe76 and Val152 of hDAT are crucial for interactions with antidepressants (Sørensen et al., 2012; Xue et al., 2018), the predicted complex of compounds $\mathbf{4 0}$ with hDAT showed that Val152 was sandwiched between the tetrazole ring and the branched monofluorobenzyl ring; Phe76 was in contact with the other monofluorobenzyl ring. The 4-benzyl ring attached to piperidine fit into the cave formed by TM1 (Trp84 and Arg85) and TM6 (Thr316 and Phe320).

Although the three-dimensional (3D) structure of hDAT was similar to that of hSERT, the binding pose of compound $\mathbf{5 4}$ differed from that of compound $\mathbf{4 0}$. Compound $\mathbf{5 4}$ fit well into the central pocket of hSERT, which was mainly enclosed by hydrophobic residues of TM1, TM3, and TM6. Unlike the binding pose of compound $\mathbf{4 0}$, the tetrazole ring of compound 54 had two significant electrostatic interactions; a hydrogen bond with Thr497 of TM8 and a weak salt bridge interaction 
Table 4. $\mathrm{IC}_{50}$ values of the selected compounds for the inhibition of 5-HT, NE, and DA reuptake

\begin{tabular}{|c|c|c|c|c|c|c|c|c|c|}
\hline Compd & $\mathrm{R} 1$ & $\mathrm{R} 2$ & $\mathrm{n}$ & $x$ & $\mathrm{~m}$ & $\mathrm{R} 3=\mathrm{R} 4$ & SERT $(\mu \mathrm{M})$ & NET $(\mu \mathrm{M})$ & DAT $(\mu \mathrm{M})$ \\
\hline 26 & $\mathrm{Cl}$ & $\mathrm{H}$ & 3 & C & 1 & $\mathrm{H}$ & ND & 0.1743 & 0.2261 \\
\hline 29 & $\mathrm{H}$ & $\mathrm{H}$ & 3 & C & 2 & $\mathrm{H}$ & ND & 0.4104 & 0.7261 \\
\hline 32 & $\mathrm{~F}$ & $\mathrm{~F}$ & 3 & C & 2 & $\mathrm{H}$ & ND & 0.3881 & 0.2493 \\
\hline 34 & $\mathrm{Cl}$ & $\mathrm{H}$ & 3 & C & 3 & $\mathrm{H}$ & ND & 0.5274 & 0.8429 \\
\hline 38 & $\mathrm{Cl}$ & $\mathrm{H}$ & 4 & C & 1 & $\mathrm{H}$ & 0.5031 & 1.04 & 0.2499 \\
\hline 39 & $\mathrm{Cl}$ & $\mathrm{Cl}$ & 4 & C & 1 & $\mathrm{H}$ & 0.6455 & 0.4689 & 0.1722 \\
\hline 40 & $\mathrm{~F}$ & $\mathrm{~F}$ & 4 & C & 1 & $\mathrm{H}$ & 0.4534 & 0.298 & 0.05789 \\
\hline 41 & $\mathrm{H}$ & $\mathrm{H}$ & 4 & C & 2 & $\mathrm{H}$ & 0.3611 & 0.2735 & 0.3831 \\
\hline 42 & $\mathrm{Cl}$ & $\mathrm{H}$ & 4 & C & 2 & $\mathrm{H}$ & 0.4614 & 0.4241 & 0.4430 \\
\hline 43 & $\mathrm{Cl}$ & $\mathrm{Cl}$ & 4 & C & 2 & $\mathrm{H}$ & 1.0330 & 1.1960 & 0.5340 \\
\hline 44 & $\mathrm{~F}$ & $\mathrm{~F}$ & 4 & C & 2 & $\mathrm{H}$ & 0.5581 & 0.3808 & 0.3297 \\
\hline 46 & $\mathrm{Cl}$ & $\mathrm{H}$ & 4 & C & 3 & $\mathrm{H}$ & 1.7090 & 0.2320 & 0.3309 \\
\hline 52 & $\mathrm{~F}$ & $F$ & 4 & C & 0 & $\mathrm{H}$ & 0.5605 & 0.6750 & 0.05567 \\
\hline 53 & $\mathrm{H}$ & $\mathrm{H}$ & 4 & C & 1 & $\mathrm{Cl}$ & 0.1285 & 0.7236 & 0.4885 \\
\hline 54 & $\mathrm{Cl}$ & $\mathrm{H}$ & 4 & C & 1 & $\mathrm{Cl}$ & 0.09031 & 0.780 & 0.5500 \\
\hline 56 & $\mathrm{~F}$ & $\mathrm{~F}$ & 4 & C & 1 & $\mathrm{Cl}$ & 0.4624 & 0.5211 & 0.6082 \\
\hline 60 & $\mathrm{~F}$ & $\mathrm{~F}$ & 4 & $\mathrm{~N}$ & 1 & $\mathrm{H}$ & 0.9907 & 0.1604 & 0.1439 \\
\hline 66 & $\mathrm{Cl}$ & $\mathrm{H}$ & 4 & $\mathrm{~N}$ & 3 & $\mathrm{H}$ & 1.0430 & 0.7450 & 0.4147 \\
\hline 70 & $\mathrm{Cl}$ & $\mathrm{H}$ & 4 & $\mathrm{~N}$ & $3^{* *}$ & $\mathrm{H}$ & 0.9460 & 0.9853 & 0.4120 \\
\hline 72 & $\mathrm{~F}$ & $\mathrm{~F}$ & 4 & $\mathrm{~N}$ & $3^{* *}$ & $\mathrm{H}$ & 0.7607 & 0.9421 & 0.3457 \\
\hline \multicolumn{7}{|c|}{ Standard drugs } & 0.2040 & 0.1100 & 0.0430 \\
\hline
\end{tabular}

Venlafaxine hydrochloride was used as a positive control for 5-HT uptake assay. GBR-12909 dihydrochloride was used as a positive drug for NE and DA reuptake. ' $n$ ' represents the carbon number in the linker between the tetrazole and piperidine group $(n=3,4)$. ' $m$ ' represents spacer between the piperidine and phenyl group $(m=1-3)$. ** represents ' $m=\left(\mathrm{CH}_{2} \mathrm{CH}=\mathrm{CH}\right)$ '. ND represents 'not determined' due to selection criteria (below relative inhibition ratio, $\%$ of inhibition $\leq 45$ ).

with Glu493 of TM8. In addition, the high aromatic tetrazole ring was stuck to hydroxyl group of Tyr175 in direction of faceto-edge. The branched benzyl ring of tetrazole was jammed between Arg104 of TM1 and Phe335 of TM4; the other monochlorobenzyl ring was surrounded by Tyr175 and Ile179 of TM3, and Leu99 of TM1. Then, Tyr175 of TM3 and Phe335 of TM4 determined the ring orientation of the branched di-benzyl ring and tetrazole. The branched benzyl ring and a four-carbon linker connected the tetrazole ring and the piperidine ring formed in an S-shape in the binding pocket of hSERT in which the nitrogen of piperidine played a key role. A boat form of the piperidine ring was laid on Tyr95 of TM1 and Phe341 of TM4. The 3,4-dichlorobenzyl-piperidine ring of 54, which was located approximately in the same plane, was firmly attached within Tyr95 of TM1, lle172, Ala173, Tyr176 of TM3 and Ser439 of TM6. Overall, the binding pose of compound $\mathbf{5 4}$ was driven by a hydrogen bond and various hydrophobic interactions, and was compactly attached in hSERT. Interestingly, when two sequences for hDAT and hSERT were aligned, Phe76, Val152, and Phe155 of hDAT, which contribute to significant hydrophobic interactions, were equivalent to Tyr95, Ile172, and Tyr175 of hSERT.

Overall, the docking simulation suggest that the binding force of hDAT is likely to be driven by shape or size-matching of a small molecule; the binding force of hSERT through formation of hydrogen bonds with a tetrazole ring and a flexible four-carbon linker. Collectively, these findings provide critical, new insights into the molecular basis and structural requirements to design potent and specific therapeutic psychiatric drugs/agents.

\section{Functional studies of dopamine reuptake inhibition}

Reuptake of the released neurotransmitters into presynaptic nerve terminals is responsible for the rapid termination of neurotransmission in the synapses (Masson et al., 1999; Torres et al., 2001). To understand the inhibition of monoamine reuptake functionally, we determined the effect of 4-benzylpiperidine carboxamides on the endocytosis of $D_{2} R$.

Agonist stimulation of $G$ protein-coupled receptors (GPCRs) induces GPCR kinase2/3-mediated receptor phosphorylation, followed by interaction with $\beta$-arrestins, which connect the receptors to adaptors, such as adaptor protein (AP)-2 and clathrin, leading to the endocytosis of GPCRs (Zhang and Kim, 2017). $D_{2} R$ also undergoes endocytosis in response to agonist stimulation (Kim et al., 2001), which reportedly mediates the resensitization of desensitized receptors (Cho et al., 

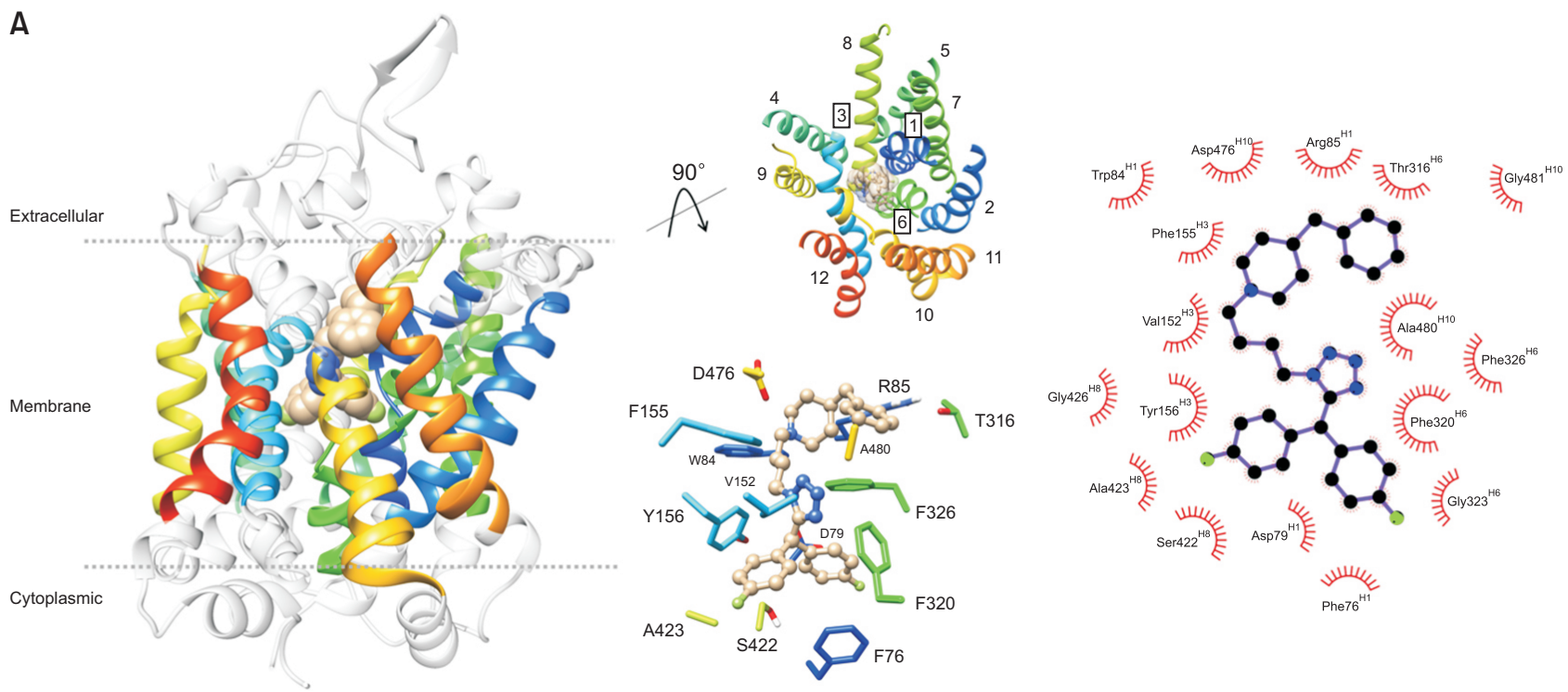

B
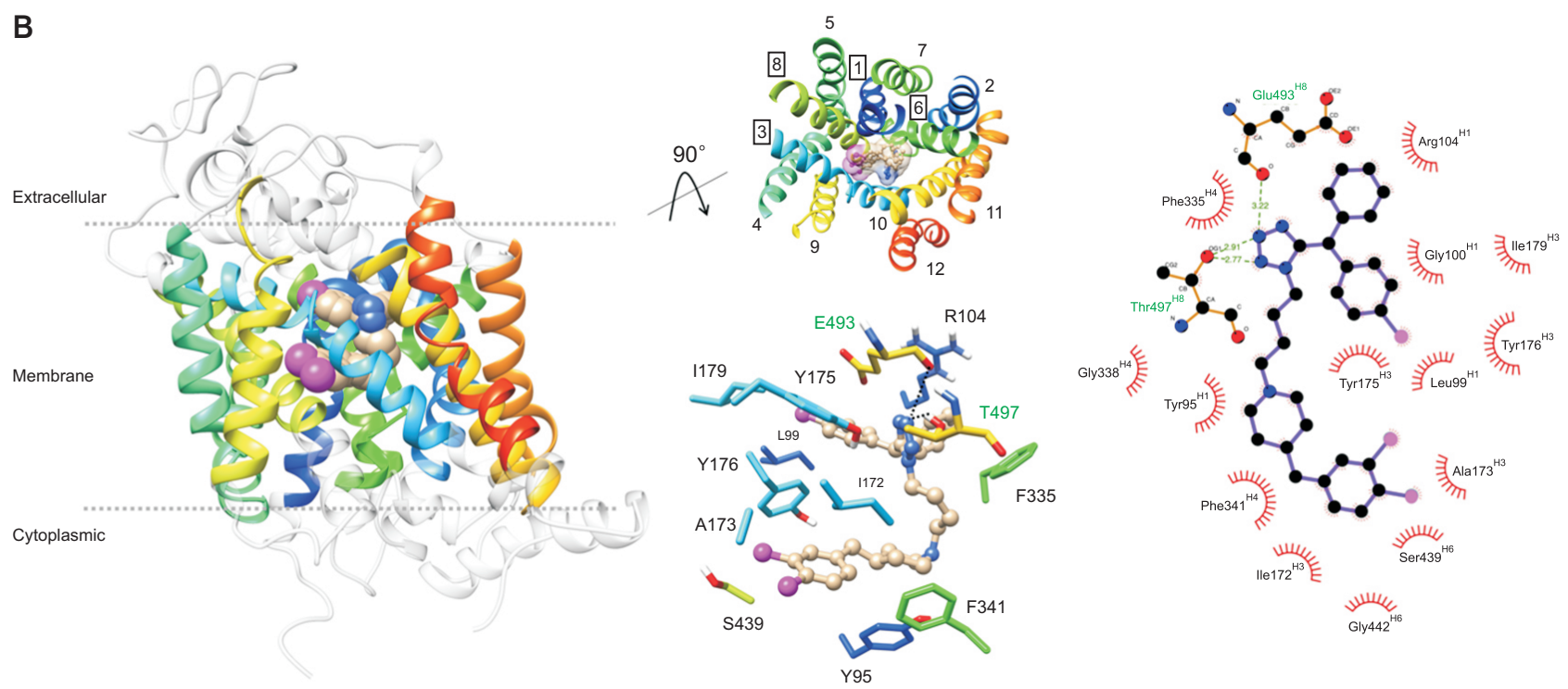

Fig. 4. Docking simulation of compounds 40 and 54 for hDAT and hSERT. A possible binding pose of $\mathbf{4 0}$ for hDAT (A) and $\mathbf{5 4}$ for hSERT (B). The 12-membrane helices were represented by rainbow colors. The spheres represent the ligand in the central pocket of the transporter. In the diagram rotated by $90^{\circ}$ (upper middle), the numbers in label indicate the number of helix and the numbers in the box represent the helices involved in the interaction with ligand. In details, the interaction between ligand-transporter was elucidated in 2-dimensional diagram and 3-dimensinal structure. The ligand was represented by ball and stick, and the side chain of residues was represented by stick and transparent sphere. The dash lines show hydrogen bond or salt-bridge interaction.

2010).

As shown in Fig. 5, treatment of the cells expressing $D_{2} R$ with $100 \mathrm{nM}$ DA for $1 \mathrm{~h}$ evoked approximately $25 \%$ of receptor endocytosis. Co-expression of hDAT significantly inhibited this endocytosis of $D_{2} R$ probably by constitutively uptaking $D A$ into the cells. When the cells were pretreated with compounds 40 and 56, hDAT-mediated inhibition of the $\mathrm{D}_{2} \mathrm{R}$ endocytosis was disinhibited in dose-dependent manner. As expected from their potencies for hDAT inhibition $\left(\mathrm{IC}_{50}\right.$ for compound $\mathbf{4 0}$ and 56 were 56 and $608 \mathrm{nM}$, respectively), compound $\mathbf{4 0}$ exerted significantly stronger disinhibitory activities than compound $\mathbf{5 6}$ on $D_{2} R$ endocytosis at $1 \mu \mathrm{M}$. Compound $\mathbf{4 0}$ fully restored the hDAT-mediated inhibition of $D_{2} R$ endocytosis at $1 \mu \mathrm{M}$. These results suggest that 1,5 -disubstituted tetrazoles can have profound influences on the signaling of monoamine neurotransmitters, for example, dopamine signaling via $D_{2} R$.

To understand the structural basis behind the difference of bioactivity between compounds $\mathbf{4 0}$ and $\mathbf{5 6}$, docking simulation was conducted for the complex between compound $\mathbf{5 6}$ and hDAT. As shown in Supplementary Fig. 2, the docking structures of compounds $\mathbf{4 0}$ and $\mathbf{5 6}$ was superimposed and their binding poses were very similar except that di-fluoride of the benzyl ring of compound $\mathbf{5 6}$ was slightly clashed with Phe320 of TM6. This difference seem to result in the lower binding affinity of compound $\mathbf{5 6}$ than compound $\mathbf{4 0 .}$. 


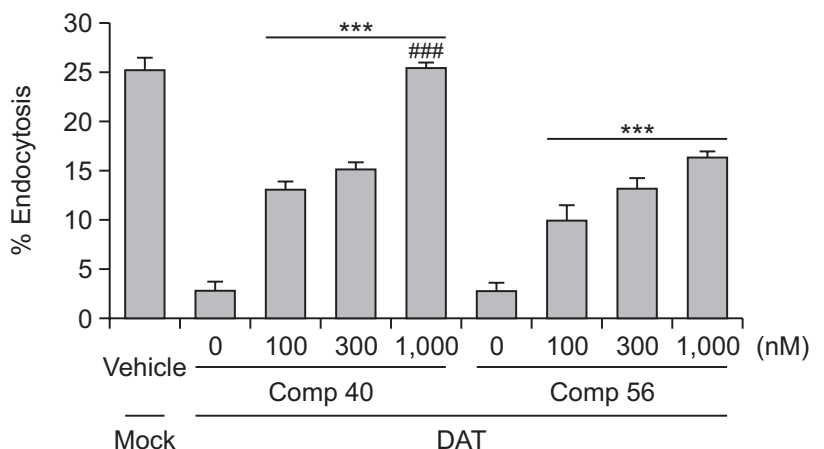

Fig. 5. Disinhibitory effects of compounds 40 and 56 on the hDATmediated inhibition of dopamine $D_{2}$ receptor endocytosis. HEK-293 cells expressing $D_{2} R$ (about $1.7 \mathrm{pmol} / \mathrm{mg}$ protein) were transfected with GRK2-pRK5 (2 $\mu \mathrm{g}$ per $100 \mathrm{~mm}$ dish) along with either mock vector or hDAT-pCMV5 (3 $\mu \mathrm{g}$ per $100 \mathrm{~mm}$ dish). Cells were pretreated with vehicle or $0-1,000 \mathrm{nM}$ compound $\mathbf{4 0}$ or $\mathbf{5 6}$ for $30 \mathrm{~min}$, followed by treatment with $100 \mathrm{nM} D A$ for $1 \mathrm{~h}$. ${ }^{* * *} p<0.001 \mathrm{com}-$

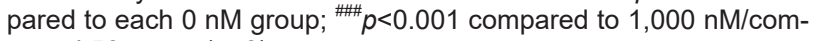
pound $\mathbf{5 6}$ group $(\mathrm{n}=3)$.

\section{DISCUSSION}

In this study, 42 tetrazole compounds were synthesized and evaluated for their inhibitory effects on reuptake of 5- $\mathrm{HT}$, $\mathrm{NE}$, and DA. After performing the primary screening at one specific concentration, $I_{50}$ values were obtained for the selected compounds through subsequent experiments. Based on these results, SAR analysis, which can suggest a direction for the development of selective inhibitors for the three transporters, was performed. Here we could suggest some principles that can help design triple reuptake inhibitors. For example, changes in the linker carbon number $(n)$ between tetrazole and piperidine, the carbon number in the spacer $(\mathrm{m})$ between piperidine and phenyl group, and the R1 and R2 phenyl ring affected the inhibitory effect of these compounds on monoamine reuptake in a diverse manner within certain rules.

The docking studies on $\mathbf{4 0}$ for hDAT and $\mathbf{5 4}$ for hSERT revealed that these compounds tightly bound to the central pocket in the target neurotransmitter transporters and formed several interactions, including edge-to-face aromatic, hydrophobic, and charge-charge interactions. Although docking simulation assumes that direct physical interactions between small molecules and transporters are the major determinant for the selectivity between transporters and compounds, it should be mentioned that in practice other indirect mechanisms could also be involved.

This study shows that DAT could inhibit the endocytosis of $D_{2} R$, which acts as an autoreceptor of dopaminergic neurons, by lowering the DA concentration in the synaptic cleft. Considering that the receptor endocytosis, including $D_{2} R$, mediates the resensitization of desensitized receptors (Yu et al., 1993, Cho et al., 2010), roles of DAT inhibitors on dopaminergic function may be more complex. the influence of DAT inhibitors can be considered complex.

DAT and its inhibitors regulate the endocytosis of $D_{2} R$ and in turn impact synaptic transmission in the dopaminergic system. DAT lowers the concentration of DA in the synaptic cleft and thus, is expected to have multiple effects on the signaling or regulatory processes of dopaminergic neurons. DAT inhibi- tors, by reversing the reuptake by DAT, are expected to trigger various pathophysiological states, including drug addiction and psychological symptoms. Even though we did not test for this in noradrenergic and serotonergic neurons, similar regulatory outcomes are expected for their synaptic transmissions.

Overall, this study provides theoretical backgrounds to identify candidate compounds with selective inhibitory effects on different monoamine transporters. In addition, the compounds characterized in this study are novel and can be utilized for developing therapeutic agents against various neuropsychiatric disorders.

\section{CONFLICT OF INTEREST}

The authors declare no financial or commercial conflict of interest.

\section{ACKNOWLEDGMENTS}

This research was supported by the Bio \& Medical Technology Development Program of the National Research Foundation (NRF) funded by the Korean government (MSIT) (NRF2017M3A9G2077568). We would like to thank the Korean Basic Science Institute Gwangju Center for performing ${ }^{1} \mathrm{H}$ NMR and ${ }^{13} \mathrm{C}$ NMR.

\section{REFERENCES}

Abraham, M. J., Murtola, T., Schulz, R., Pãll, S., Smith, J. C., Hess, B. and Lindahl, E. (2015) GROMACS: high performance molecular simulations through multi-level parallelism from laptops to supercomputers. SoftwareX 1-2, 19-25.

Belmaker, R. H. and Agam, G. (2008) Major depressive disorder. N. Engl. J. Med. 358, 55-68.

Burger, A. (1991) Isosterism and bioisosterism in drug design. Prog. Drug Res. 37, 287-371.

ChemAxon (2014) MarvinSketch (version 6.2.2), calculation module developed by ChemAxon. Available from: http://www.chemaxon. com/products/marvin/marvinsketch/.

Cho, D., Zheng, M., Min, C., Ma, L., Kurose, H., Park, J. H. and Kim, K. M. (2010) Agonist-induced endocytosis and receptor phosphorylation mediate resensitization of dopamine $\mathrm{D}(2)$ receptors. Mol. Endocrinol. 24, 574-586.

Coleman, J. A., Green, E. M. and Gouaux, E. (2016) X-ray structures and mechanism of the human serotonin transporter. Nature $\mathbf{5 3 2}$, 334-339.

Dahlof, B., Devereux, R. B., Kjeldsen, S. E., Julius, S., Beevers, G., De Faire, U., Fyhrquist, F., Ibsen, H., Kristiansson, K., LederballePedersen, O., Lindholm, L. H., Nieminen, M. S., Omvik, P., Oparil, S. and Wedel, H.; LIFE Study Group (2002) Cardiovascular morbidity and mortality in the Losartan Intervention For Endpoint reduction in hypertension study (LIFE): a randomised trial against atenolol. Lancet 359, 995-1003.

Dhayanithi, V., Shafi Syed, S., Kumaran, K., Jai Sankar, K. R., Ragavan Venkat, R., Goud Kumar Sanath, P., Kumari Suchetha, N. and Pati Hari, N. (2011) Synthesis of selected 5-thio-substituted tetrazole derivatives and evaluation of their antibacterial and antifungal activities. J. Serb. Chem. Soc. 76, 165-175.

El-Sayed, W. A., El-Kosy, S. M., Ali, O. M., Emselm, H. M. and AbdelRahman, A. A. (2012) Anticancer activity of new (tetrazol-5-yl)methylindole derivatives and their acyclic c-nucleoside analogs. Acta Pol. Pharm. 69, 669-677.

Gao, Y. L., Zhao, G. L., Liu, W., Shao, H., Wang, Y. L., Xu, W. R., Tang, L. D. and Wang, J. W. (2010) Design, synthesis and in vivo 
hypoglycemic activity of tetrazole-bearing N-glycosides as SGLT2 inhibitors. Indian. J. Chem. 49B, 1499-1508.

Herr, R. J. (2002) 5-Substituted-1H-tetrazoles as carboxylic acid isosteres: medicinal chemistry and synthetic methods. Bioorg. Med. Chem. 10, 3379-3393.

Hess, B., Bekker, H., Berendsen, H. J. C. and Fraaije, J. G. E. M. (1997) LINCS: a linear constraint solver for molecular simulations. J. Comput. Chem. 18, 1463-1472.

Hirschfeld, R. M. (2000) History and evolution of the monoamine hypothesis of depression. J. Clin. Psychiatry 61 Suppl 6, 4-6.

Holtzheimer, P. E., 3rd and Nemeroff, C. B. (2006) Advances in the treatment of depression. NeuroRx 3, 42-56.

Hutchinson, D. W. and Naylor, M. (1985) The antiviral activity of tetrazole phosphonic acids and their analogues. Nucleic Acids Res. 13, 8519-8530.

Ichikawa, T., Kitazaki, T., Matsushita, Y., Hosono, H., Yamada, M., Mizuno, M. and Itoh, K. (2000) Optically active antifungal azoles. XI. An alternative synthetic route for 1-[(1R, 2R)-2-(2, 4-difluorophenyl)-2hydroxy-1-methyl-3-(1H-1, 2, 4-triazol-1-yl)propyl]-3-[4-(1H-1-tetrazolyl)phenyl]-2-imidazolidinone (TAK-456) and its analog. Chem. Pharm. Bull. 48, 1947-1953.

Iversen, L. (2006) Neurotransmitter transporters and their impact on the development of psychopharmacology. Br. J. Pharmacol. 147 Suppl 1, S82-S88.

John, E. O., Kirchmeier, R. L. and Shreeve, J. M. (1989) Reactions of 5-(perfluoroalkyl)tetrazolates with cyanogen, nitrosyl, and cyanuric chlorides. Inorg. Chem. 28, 4629-4633.

Jorgensen, W. L., Chandrasekhar, J. and Madura, J. D. (1983) Comparison of simple potential functions for simulating liquid water. $J$. Chem. Phys. 79, 926.

Kim, K. M., Valenzano, K. J., Robinson, S. R., Yao, W. D., Barak, L. S. and Caron, M. G. (2001) Differential regulation of the dopamine D2 and D3 receptors by $\mathrm{G}$ protein-coupled receptor kinases and betaarrestins. J. Biol. Chem. 276, 37409-37414.

Klapötke, T. M., Stierstorfer, J. and Weber, B. (2009) New energetic materials: synthesis and characterization of copper 5-nitriminotetrazolates. Inorg. Chim. Acta 362, 2311-2320.

Kulkarni, S. K. and Dhir, A. (2009) Current investigational drugs for major depression. Expert Opin. Investig. Drugs 18, 767-788.

Laskowski, R. A. and Swindells, M. B. (2011) LigPlot+: multiple ligandprotein interaction diagrams for drug discovery. J. Chem. Inf. Model. 51, 2778-2786.

Le Bourdonnec, B., Meulon, E., Yous, S., Goossens, J. F., Houssin, R. and Henichart, J. P. (2000) Synthesis and pharmacological evaluation of new pyrazolidine-3, 5-diones as AT(1) angiotensin II receptor antagonists. J. Med. Chem. 43, 2685-2697.

Maier, J. A., Martinez, C., Kasavajhala, K., Wickstrom, L., Hauser, K. E. and Simmerling, C. (2015) ff14SB: improving the accuracy of protein side chain and backbone parameters from ff99SB. J. Chem. Theory Comput. 11, 3696-3713.

Martirosyan, A. O., Aleksanyan, M. V., Terzyan, S. S., Ter-Zakharyan, Y. Z., Agababyan, R. V., Karapetyan, A. A., Mndzhoyan, S. L. and Tamazyan, R. A. (2001) Synthesis and molecular and crystal structure of 1-(5-benzyl-2-tetrazolyl)-1-cyclopentanecarboxylic acid. penicillin and cephalosporins based on this acid. Pharm. Chem. J. 35, 169-171.

Masson, J., Sagne, C., Hamon, M. and El Mestikawy, S. (1999) Neurotransmitter transporters in the central nervous system. Pharmacol. Rev. 51, 439-464.

Mosmann, T. (1983) Rapid colorimetric assay for cellular growth and survival: application to proliferation and cytotoxicity assays. J. Immunol. Methods 65, 55-63.

Paudel, S., Acharya, S., Yoon, G., Kim, K. M. and Cheon, S. H. (2017a) Design, synthesis and in vitro activity of 1,4-disubstituted piperazines and piperidines as triple reuptake inhibitors. Bioorg. Med. Chem. 25, 2266-2276.

Paudel, S., Cao, Y., Guo, S., An, B., Kim, K. M. and Cheon, S. H. (2015) Design and synthesis of 4-benzylpiperidine carboxamides as dual serotonin and norepinephrine reuptake inhibitors. Bioorg. Med. Chem. 23, 6418-6426.

Paudel, S., Kim, E., Zhu, A., Acharya, S., Min, X., Cheon, S. H. and
Kim, K. M. (2021) Structural requirements for modulating 4-benzylpiperidine carboxamides from serotonin/norepinephrine reuptake inhibitors to triple reuptake inhibitors. Biomol. Ther. (Seoul) 29, 392-398.

Paudel, S., Min, X., Acharya, S., Khadka, D. B., Yoon, G., Kim, K. M. and Cheon, S. H. (2017b) Triple reuptake inhibitors: design, synthesis and structure-activity relationship of benzylpiperidinetetrazoles. Bioorg. Med. Chem. 25, 5278-5289.

Pegklidou, K., Koukoulitsa, C., Nicolaou, I. and Demopoulos, V. J. (2010) Design and synthesis of novel series of pyrrole based chemotypes and their evaluation as selective aldose reductase inhibitors. A case of bioisosterism between a carboxylic acid moiety and that of a tetrazole. Bioorg. Med. Chem. 18, 2107-2114.

Pettersen, E. F., Goddard, T. D., Huang, C. C., Couch, G. S., Greenblatt, D. M., Meng, E. C. and Ferrin, T. E. (2004) UCSF Chimera--a visualization system for exploratory research and analysis. J. Comput. Chem. 25, 1605-1612.

Prins, J., Olivier, B. and Korte, S. M. (2011) Triple reuptake inhibitors for treating subtypes of major depressive disorder: the monoamine hypothesis revisited. Expert Opin. Investig. Drugs 20, 1107-1130.

Rajasekaran, A. and Thampi, P. P. (2004) Synthesis and analgesic evaluation of some 5-[beta-(10-phenothiazinyl)ethyl]-1-(acyl)1,2,3,4-tetrazoles. Eur. J. Med. Chem. 39, 273-279.

Singh, H., Chawla, A. S., Kapoor, V. K., Paul, D. and Malhotra, R. K. (1980) Medicinal chemistry of tetrazoles. Prog. Med. Chem. 17, $151-183$.

Sørensen, L., Andersen, J., Thomsen, M., Hansen, S. M., Zhao, X., Sandelin, A., Strømgaard, K. and Kristensen, A. S. (2012) Interaction of antidepressants with the serotonin and norepinephrine transporters: mutational studies of the $\mathrm{S} 1$ substrate binding pocket. J. Biol. Chem. 287, 43694-43707.

Sprenger, K. G., Jaeger, V. W. and Pfaendtner, J. (2015) The general AMBER force field (GAFF) can accurately predict thermodynamic and transport properties of many ionic liquids. J. Phys. Chem. B 119, 5882-5895.

Subbaiah, M. A. M. (2018) Triple reuptake inhibitors as potential therapeutics for depression and other disorders: design paradigm and developmental challenges. J. Med. Chem. 61, 2133-2165.

Torres, G. E., Yao, W. D., Mohn, A. R., Quan, H., Kim, K. M., Levey, A. I., Staudinger, J. and Caron, M. G. (2001) Functional interaction between monoamine plasma membrane transporters and the synaptic PDZ domain-containing protein PICK1. Neuron 30, 121-134.

Trott, O. and Olson, A. J. (2010) AutoDock Vina: improving the speed and accuracy of docking with a new scoring function, efficient optimization, and multithreading. J. Comput. Chem. 31, 455-461.

Vieira, E., Huwyler, J., Jolidon, S., Knoflach, F., Mutel, V. and Wichmann, J. (2005) 9H-Xanthene-9-carboxylic acid [1,2,4]oxadiazol3-yl- and (2H-tetrazol-5-yl)-amides as potent, orally available mGlu1 receptor enhancers. Bioorg. Med. Chem. Lett. 15, 46284631.

Wagle, S., Adhikari, A. V. and Kumari, N. S. (2009) Synthesis of some new 4-styryltetrazolo[1,5-a]quinoxaline and 1-substituted4-styryl[1,2,4]triazolo[4,3-a]quinoxaline derivatives as potent anticonvulsants. Eur. J. Med. Chem. 44, 1135-1143.

Wagner, D., Wellmer, F., Dilks, K., William, D., Smith, M. R., Kumar, P. P., Riechmann, J. L., Greenland, A. J. and Meyerowitz, E. M. (2004) Floral induction in tissue culture: a system for the analysis of LEAFY-dependent gene regulation. Plant J. 39, 273-282.

Wang, K. H., Penmatsa, A. and Gouaux, E. (2015) Neurotransmitter and psychostimulant recognition by the dopamine transporter. Nature 521, 322-327.

Waterhouse, A., Bertoni, M., Bienert, S., Studer, G., Tauriello, G., Gumienny, R., Heer, F. T., de Beer, T. A. P., Rempfer, C., Bordoli, L., Lepore, R. and Schwede, T. (2018) SWISS-MODEL: homology modelling of protein structures and complexes. Nucleic Acids Res. 46, W296-W303.

Xue, W., Wang, P., Tu, G., Yang, F., Zheng, G., Li, X., Li, X., Chen, Y., Yao, X. and Zhu, F. (2018) Computational identification of the binding mechanism of a triple reuptake inhibitor amitifadine for the treatment of major depressive disorder. Phys. Chem. Chem. Phys. 20, 6606-6616. 
Yu, S. S., Lefkowitz, R. J. and Hausdorff, W. P. (1993) Beta-adrenergic receptor sequestration. A potential mechanism of receptor resensitization. J. Biol. Chem. 268, 337-341.
Zhang, X. and Kim, K. M. (2017) Multifactorial regulation of G proteincoupled receptor endocytosis. Biomol. Ther. (Seoul) 25, 26-43. 